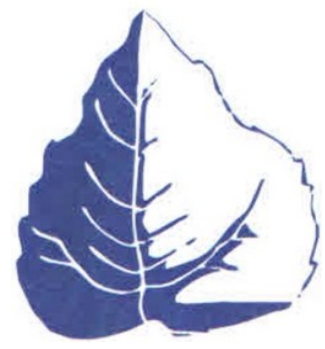

УДК 332.2

\section{ЭКОЛОГИЯ (ПО ОТРАСЛЯМ) ECOLOGY (ITS BRUNCHES)}

https://doi.org/10.23947/2413-1474-2021-5-3-38-46

Методологические основы концепции воспроизводства плодородия почв

Тарасов А. C. ${ }^{1}$, Тарасов C. A. ${ }^{2}$

${ }^{1}$ ФББУ ГЦАС «Ростовский» (пос. Рассвет, Российская Федерация)

${ }^{2}$ Новочеркасский колледж промышленных технологий и управления (г. Новочеркасск, Российская Федерация)

Вопросы воспроизводства плодородия почв обычно рассматриваются как система конкретных мероприятий. В данной статье представлен несколько иной подход, сущность которого заключается в обосновании методологии построения концепции воспроизводства плодородия, в формулировании цели, задач, в определении способа формирования индикативных показателей и в оценке эффективности. Представлены данные по Ростовской области о динамике баланса элементов питания в почве и оценке эффективности изменения структуры посевных площадей.

Ключевые слова: концепция, программа, плодородие, цели концепции, система индикативных показателей, эффективность воспроизводства плодородия.

Для цитирования: Тарасов, А. С. Методологические основы концепции воспроизводства плодородия почв / А. С. Тарасов, С. А. Тарасов // Экономика и экология территориальных образований. - 2021. - Т. 5, № 3. - С. 38-46. https://doi.org/10.23947/2413-1474-2021-5-3-38-46

\title{
Methodological foundations of soil fertility reproduction concept
}

Tarasov A. S. ${ }^{1}$, Tarasov S. A. ${ }^{2}$

${ }^{1}$ FSBU SCAS "Rostovskiy" (Rassvet, Russian Federation)

${ }^{2}$ Novocherkassk College of Industrial Technologies and Management (Novocherkassk, Russian Federation)

The issues of soil fertility reproduction are usually considered as a system of specific measures. This article presents a slightly different approach, the essence of which is to substantiate the methodology for constructing the concept of fertility reproduction, to formulate goals, tasks, to determine the method of forming indicative indicators and to assess effectiveness. The data for the Rostov region on the dynamics of nutrients balance in the soil and the assessment of the effectiveness of changing the structure of sown areas are presented.

Keywords: concept, program, fertility, goals of the concept, system of indicative indicators, efficiency of fertility reproduction.

For citation: A. S. Tarasov, S. A.Tarasov. Methodological foundations of soil fertility reproduction concept. Economy and ecology of territorial formations, 2021, vol. 5, no 3, pp. 38-46. https://doi.org/10.23947/2413-1474-2021-5-3-38-46

Введение. Подготовка государственных и ведомственных программ в соответствии с законом о стратегическом планировании предусматривает разработку концепций этих программ. В новейшей истории концепции разрабатывались для двух программ федерального 
уровня («Сохранение и восстановление плодородия почв земель сельскохозяйственного назначения и агроландшафтов как национального достояния России на 2006-2010 годы и на период до 2013 года» и «Развитие мелиорации земель сельскохозяйственного назначения России на 2014-2020 годы»).

Отправной точкой любой концепции является формулировка ее цели. В концепции к программе «Плодородие...» цель четко не сформулирована, хотя раздел с названием «Цели и задачи.... там есть. В этом разделе приводится следующая формулировка: «В настоящей Концепции представлен комплекс мер по воздействию на химические, физические и биологические процессы, протекающие в почве сельскохозяйственных угодий и растениях, с целью реализации генетического и биоклиматического потенциала по количеству и качеству продукции выращиваемых культур. Центральное место отводится применению агрохимических средств (удобрений и химических мелиорантов), ибо без них невозможно регулировать биологический круговорот веществ в агроэкосистемах, сохранить и обеспечить расширенное воспроизводство почвенного плодородия в рамках экологической безопасности и экономической целесообразности» [1]. Из текста приведенного фрагмента можно сделать вывод о том, что целью является реализация генетического и биоклиматического потенциала выращиваемых культур, то есть повышение урожайности в основном за счет применения удобрений, а внесение удобрений должно обеспечить воспроизводство плодородия почв.

В концепции к программе «Мелиорация...» записано, что «Целями Программы являются повышение продуктивности и устойчивости сельскохозяйственного производства и плодородия почв средствами комплексной мелиорации» [2]. Приоритет роста продуктивности и устойчивости производства находится на первом месте, а плодородие вторично.

По мнению авторов, обеспечить рост производства можно разными путями, в том числе и за счет повышения уровня эксплуатации плодородия, что мы и наблюдаем на протяжении длительного периода времени. В обозримой перспективе на концептуальном уровне должна ставиться цель сохранения нейтрального (нулевого) уровня деградации сельскохозяйственных угодий, и на этой основе необходимо рассматривать мероприятия по наращиванию объемов производства.

Система сохранения и воспроизводства плодородия почв сельскохозяйственных угодий должна представлять собой комплекс взаимоувязанных и взаимодополняющих организационно-управленческих, агрохимических, агротехнических, агролесомелиоративных, мелиоративных, противоэрозионных, культуртехнических и прочих мероприятий, обеспечивающих достижение нейтрального (нулевого) уровня деградации сельскохозяйственных угодий.

Цель системы заключается в организации процесса взаимодействия всех ее составных частей и элементов для сохранения нейтрального (нулевого) уровня деградации сельскохозяйственных угодий и обеспечения эффективного использования земель.

Основная часть. Общий состав конкретных задач очень обширен, и на уровне концепции можно ограничиться обзором основных направлений, из которых при разработке документов следующего уровня будут формулироваться конкретные задачи.

На уровне концепции задачи системы можно представить в виде «дерева целей», основными составными частями которого выступают три направления деятельности:

— определение состава и содержания функций управления воспроизводством плодородия;

— формирование системы обеспечения; 
— организация управления деятельностью по сохранению и воспроизводству плодородия.

Центральное место в этой системе занимают базовые функции управления, которые включают в себя:

1. Изучение состояния земель (агрохимическое, эколого-токсикологическое и другие виды обследования земель).

2. Создание и ведение ГИС земель (мониторинг земель сельскохозяйственного назначения).

3. Прогнозирование изменений в состоянии и использовании земель (ежегодный доклад о состоянии плодородия земель сельскохозяйственного назначения).

4. Планирование и экономическое стимулирование осуществления мероприятий по охране и воспроизводству плодородия земель сельскохозяйственного назначения.

5. Разработка проектов использования земель (агроэкологическое районирование земель сельских поселений, разработка проектов адаптивно-ландшафтного земледелия).

6. Контроль выполнения плановых мероприятий и состояния использования земель (муниципальный и общественный контроль, государственный надзор).

Система обеспечения включает в себя правовое, финансовое, кадровое, научное и PRобеспечение. Организация управления заключатся в закреплении функций управления за конкретными исполнителями и в обеспечении их необходимыми ресурсами. Каждая базовая функция и каждое направление обеспечения выступают объектом для анализа современного состояния, последующей декомпозиции и доведения задачи до уровня, при котором они обретают конкретное количественное измерение, сроки исполнения, источники и объемы ресурсов и исполнителей. Процесс реализации задач системы представлен на рис. 1 в виде схемы последовательности действий по сохранению и воспроизводству плодородия почв. Фундаментом системы выступает блок анализа современного состояния процессов, происходящих в области плодородия. Этот анализ является основанием для постановки задач, и эти задачи можно разделить на две группы. В первую группу включаются задачи текущего регулирования процессов воспроизводства плодородия, это задачи, которые можно решить в течение двух-трех лет и оценить их результаты в течение следующих двух-трех лет. Вместе с тем, решение задач текущего регулирования не обеспечит решения стратегических задач перехода к нулевому уровню процессов деградации почв.

Задачи стратегического развития нацелены на стабилизацию положительных тенденций в процессах перехода от деградации почв к стабильному воспроизводству плодородия.

Центральное место в данной схеме сохранения и воспроизводства плодородия почв отводится набору мероприятий, которые реализуют задачи как текущего регулирования, так и стратегического развития. Разграничивать мероприятия в соответствии с типом задач не целесообразно, так как их содержание представляет собой единый комплекс последовательного решения проблем сохранения и воспроизводства плодородия почв.

Реализация мероприятий предусматривает наличие блока обеспечения, включающего в себя научное, кадровое, финансовое и информационное обеспечение.

Результаты реализации мероприятий оцениваются с помощью системы индикативных показателей и показателей экономической эффективности. Если получаемые результаты не соответствуют заданным параметрам, то возникает необходимость внести коррективы в содержание мероприятий. Достижение заданных параметров означает и достижение основной цели системы. 
Системный подход к реализации мероприятий по сохранению и восстановлению плодородия почв в полном объеме не выполнялся никогда несмотря на то, что на всех этапах исторического развития аграрная политика уделяла внимание вопросам сохранения и воспроизводства плодородия почв.

Конкретизация этой политики на разных временных этапах была разной и отражала в себе возможности и общие подходы государства к регулированию аграрных отношений.

На современном этапе аграрная политика в сфере сохранения и воспроизводства плодородия почв реализовывалась в форме целевых и государственных программ, таких как ФЦП «Сохранение и восстановление плодородия почв земель сельскохозяйственного назначения и агроландшафтов как национального достояния России на 2006-2010 годы и на период до 2013 года» и ее продолжения - ФЦП «Развитие мелиорации земель сельскохозяйственного назначения России на 2014-2020 годы». На уровне Ростовской области эти программы трансформировались в мероприятия и включены в программу «Развитие сельского хозяйства и регулирование рынков сельскохозяйственной продукции, сырья и продовольствия».

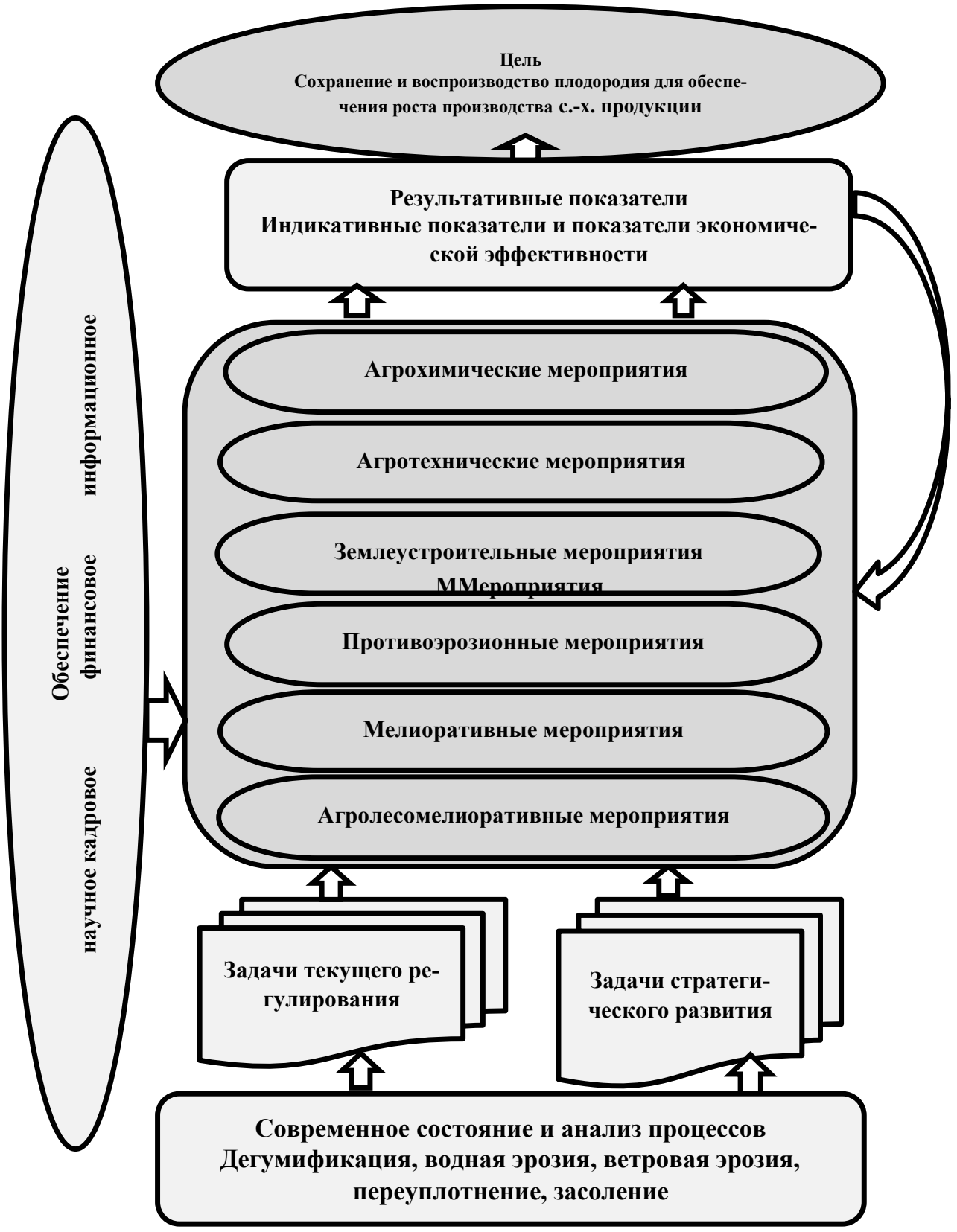

Рис. 1. Система сохранения и воспроизводства плодородия почв 
Реализация этих программ способствовала росту эффективности использования земель, но общий вынос элементов питания практически в два раза превышает их поступление с удобрениями и растительными остатками.

Баланс элементов питания в земледелии Ростовской области остается стабильно отрицательным (табл. 1).

Таблица 1

Баланс элементов питания на пахотных землях Ростовской области

\begin{tabular}{|c|c|c|}
\hline Годы & Баланс элементов питания, кг д.в/га & $\begin{array}{c}\text { Возмещение элементов питания, } \\
\%\end{array}$ \\
\hline 2013 & $-372,0$ & 56,0 \\
\hline 2014 & $-164,0$ & 51,8 \\
\hline 2015 & $-85,7$ & 53,4 \\
\hline 2016 & $-116,2$ & 37,8 \\
\hline 2017 & $-140,8$ & 44,7 \\
\hline 2018 & $-93,3$ & 57,1 \\
\hline 2019 & $-132,5$ & 46,9 \\
\hline
\end{tabular}

Анализ тенденций роста объемов внесения минеральных удобрений и урожайности за последние 20 лет показывает, что объем внесения удобрений вырос с 7 кг действующего вещества на гектар до 74 кг, а урожайность зерновых возросла с 14,7 ц/га до 34,6 ц/га. Объемы внесения удобрений увеличились в 10 раз, а урожайность выросла в 2,5 раза.

Объемы внесения органических удобрений можно вообще не учитывать, так как площадь, на которую они вносятся, не превышает 2\% площади посевов. Представленные данные наглядно свидетельствуют о том, что только наращивание применения минеральных удобрений не сможет обеспечить экономически обоснованный и технологически реализуемый рост плодородия и урожайности. В сложившейся ситуации необходим поиск новых подходов к обеспечению роста производства сельскохозяйственной продукции при сохранении важнейшего национального достояния - плодородия почв.

Важным элементом концепций является вариантный подход к решению проблемы. В концепциях программ «Плодородие...» и «Мелиорация...» варианты формировались в зависимости от объемов финансирования. Такой подход на концептуальном уровне не приемлем. В концепции должны рассматриваться способы или подходы к достижению цели, а не направления использования бюджетных средств. Негативным последствием такого подхода при реализации программ стало систематическое снижение объемов финансирования при соответствующей корректировке индикативных показателей, а в итоге мы видим перевыполнение плановых показателей, хотя их абсолютные величины в разы меньше заявленных при обосновании программ.

Реализацию концепции в форме программы можно рассматривать в трех вариантах:

Вариант 1. Продолжение реализации мероприятий, которые были в прошлых программах (инерционный вариант).

Вариант 2. Постепенная трансформация структуры посевных площадей, направленная на увеличение доли многолетних трав, субсидирование внедрения почвоохранных технологий, внесение фосфорсодержащих удобрений и проведение экспериментальных работ по внедрению адаптивно-ландшафтной организации территории (базовый вариант).

Вариант 3. Разработка проектов адаптивно-ландшафтной организации территории и 
субсидирование реализации комплекса мероприятий, предусмотренных в данных проектах (инновационный вариант).

Системность концепции сохранения и восстановления плодородия почв земель сельскохозяйственного назначения самым непосредственным образом связана с развитием животноводства, так как без увеличения объемов внесения органических удобрений решить проблемы плодородия почв невозможно.

Современное состояние и оценка возможных перспектив в проведении работ по сохранению и воспроизводству плодородия почв наиболее наглядно можно представить в форме лепестковой диаграммы, лепестками которой будут выступать направления деятельности, а показатели по конкретному направлению будут отражать уровень решения проблем данного направления (табл. 2).

Таблица 2

Состояние и оценка возможных перспектив в проведении работ по сохранению и воспроизводству плодородия почв

\begin{tabular}{|c|c|}
\hline $\begin{array}{c}\text { Направления деятельности по сохране- } \\
\text { нию и воспроизводству плодородия } \\
\text { почв }\end{array}$ & Характеристики состояния (индикативные показатели) \\
\hline Внесение минеральных удобрений & \% от потребности для планируемой урожайности \\
\hline Внесение органических удобрений & \% от потребности для планируемой урожайности \\
\hline Соблюдение системы севооборотов & $\begin{array}{l}\text { \% отклонения от рекомендованной зональной системы } \\
\text { земледелия }\end{array}$ \\
\hline Агротехнические мероприятия & $\begin{array}{l}\text { \% территории, на которой выполняются противоэрози- } \\
\text { онные мероприятия }\end{array}$ \\
\hline Агролесомелиоративные мероприятия & $\begin{array}{l}\text { \% площади, защищенной лесными полосами; } \\
\text { состояние лесных полос }\end{array}$ \\
\hline Техническое обеспечение & $\begin{array}{l}\text { \% обеспеченности техникой для приготовления и внесе- } \\
\text { ния удобрений (с возможной детализацией) }\end{array}$ \\
\hline $\begin{array}{l}\text { Строительство и реконструкция проти- } \\
\text { воэрозионных сооружений }\end{array}$ & $\begin{array}{l}\text { \% площади, защищенной этими сооружениями, от общей } \\
\text { площади, нуждающейся в защите такими сооружениями }\end{array}$ \\
\hline Организация территории & $\begin{array}{l}\text { \% площади, на которую разработаны проекты организа- } \\
\text { ции территории для освоения адаптивно-ландшафтной } \\
\text { системы земледелия }\end{array}$ \\
\hline Информационное обеспечение & $\begin{array}{l}\text { \% территории, на которую имеется актуальная информа- } \\
\text { ция о состоянии плодородия почв }\end{array}$ \\
\hline $\begin{array}{l}\text { Экономическое стимулирование вы- } \\
\text { полнения мероприятий по сохранению } \\
\text { плодородия }\end{array}$ & $\begin{array}{l}\text { \% дотаций на мероприятия по воспроизводству плодоро- } \\
\text { дия в общем объеме датирования отрасли; } \\
\text { конкретные показатели финансирования мероприятий, } \\
\text { связанных с воспроизводством плодородия; } \\
\text { экспертная оценка уровня значимости экономических } \\
\text { стимулов для землепользователя }\end{array}$ \\
\hline Правовое обеспечение & $\begin{array}{l}\text { Уровень достаточности нормативно-правовых актов для } \\
\text { осуществления мероприятий по сохранению плодородия } \\
\text { почв }\end{array}$ \\
\hline Научное обеспечение & $\begin{array}{l}\text { Количество и объемы финансируемых направлений ис- } \\
\text { следований; } \\
\text { экспертная оценка состояния научного обеспечения ме- } \\
\text { роприятий }\end{array}$ \\
\hline
\end{tabular}


В процессе разработки программы по каждому направлению можно будет определить количественные параметры. В качестве примера рассмотрим порядок определения показателей к направлению «Соблюдение системы севооборотов» (табл. 3).

Таблица 3

Посевные площади основных сельскохозяйственных культур в Ростовской области

\begin{tabular}{|c|c|c|c|}
\hline Группа культур, культура & $\begin{array}{c}\text { Рекомендуемые } \\
\text { в системе земле- } \\
\text { делия на 2020 год }\end{array}$ & $\begin{array}{c}\text { Фактические } \\
\text { в 2019 году }\end{array}$ & $\begin{array}{c}\text { Отклонение факти- } \\
\text { ческих площадей } \\
\text { от рекомендуемых }\end{array}$ \\
\hline Пашня, тыс. га. & 5780,6 & 5870,5 & 89,9 \\
\hline Пары чистые, тыс. га & 930 & 1162,2 & $-232,2$ \\
\hline \% к пашне & 16,1 & 19,8 & $-3,7$ \\
\hline Посевная площадь, всего, тыс. га & 4850,6 & 4648,5 & 202,1 \\
\hline Зерновые и зернобобовые, всего & 3500 & 3551,5 & $-51,5$ \\
\hline Озимые на зерно, из них & 2500 & 2934,1 & $-434,1$ \\
\hline озимая пшеница & 2400 & 2808,9 & $-408,9$ \\
\hline Яровые зерновые, из них & 1000 & 681,3 & 318,7 \\
\hline подсолнечник & 550 & 739,4 & $-198,4$ \\
\hline Многолетние травы & 150 & 122,5 & 27,5 \\
\hline
\end{tabular}

По представленным в табл. 3 данным видно, что наиболее существенные отклонения по площади паров озимой пшеницы и подсолнечника. Отклонение по площади паров составляет $25 \%$, по площади посевов озимой пшеницы - 17\%, по подсолнечнику $-34 \%$. При определении целевых показателей необходимо будет установить научно обоснованные предельно допустимые проценты отклонения фактических значений от рекомендуемых.

Заключение. Оценка эффективности системы сохранения и воспроизводства плодородия почв. Выход на траекторию расширенного воспроизводства плодородия почв за счет реализации комплекса мероприятий, предлагаемых в концепции, позволит повысить продуктивность сельскохозяйственных угодий, обеспечить устойчивость производства сельскохозяйственной продукции независимо от климатических изменений.

Эффективность системы сохранения и воспроизводства плодородия почв необходимо рассматривать в двух аспектах: как сохранение национального достояния и как средство производства.

В первую очередь сохранение и воспроизводство плодородия почв следует рассматривать как сохранение национального достояния. По этому направлению оценивать эффективность можно только на основе сопоставления планируемых и фактически выполняемых мероприятий.

При оценке эффективности воспроизводства земли как средства производства можно использовать традиционную методологию сопоставления затрат и результатов с учетом специфики вклада земли в результат производства. 
До определения состава и объема конкретных мероприятий масштаб экономической эффективности воспроизводства плодородия можно рассчитать через оценку стоимости выноса элементов питания из почвы и приведение структуры посевных площадей к научно обоснованным и рекомендованным в зональной системе земледелия нормам.

В 2019 году баланс элементов питания показал превышение выноса NPK в объеме 132,5 кг/га в д. в. Стоимость действующего вещества в разных видах удобрений около 50 руб. за кг. При такой цене получается, что в 2019 году за счет истощения почвы с каждого гектара пашни изъято по 6,6 тыс. рублей, а со всей площади пашни - около 38 млрд руб.

Основным показателем нарушения севооборотов является превышение посевных площадей озимой пшеницы и подсолнечника. Эти культуры обеспечивают основной приток денежных средств хозяйствующим субъектам и в то же время толкают их на нарушение севооборотов, порождая хищническое отношение к земле, то есть ради сиюминутной выгоды приносится в жертву будущее.

В 2019 году посевы озимой пшеницы составили 2808,9 тыс. га, при научно обоснованной площади - 2400 тыс. га, то есть превышение составило 408,9 тыс. га. При средней урожайности 35,9 ц /га с этой площади было получено около 1,5 млн тонн зерна, а в денежном выражении (цена на зерно в 20019 году составила 10360 руб. за т) - 15,5 млрд руб. Общие затраты на дополнительную площадь составили 10,8 млрд руб.

Отрицательный баланс элементов питания с одного га, рассчитанный на основе балансового метода, эквивалентен потере тонны зерна с гектара.

При соблюдении рекомендованной площади посевов озимой пшеницы и соблюдении нулевого баланса по элементам питания растений потребовалось бы дополнительно на удобрения около 15,8 млрд руб., это на 5 млрд руб. больше, чем потрачено на дополнительно засеянную площадь. Прирост объема зерна составил бы 2,5 млн тонн, в денежном выражении (по ценам 2019 года) - 25 млрд рублей. В итоге получается, что выручка хозяйствующих субъектов возрастает на 20 млрд рублей (в среднем на 8,3 тыс. руб. с га), и при этом сохраняется нулевой баланс выноса элементов питания, и высвобождается 400 тыс. га для посевов других культур.

\section{Библиографический список}

1. Об утверждении Концепции федеральной целевой программы «Сохранение и восстановление плодородия почв земель сельскохозяйственного назначения и агроландшафтов как национального достояния России на 2006-2010 годы» : распоряжение Правительства РФ от1 октября 2005 года № 1564-р / Гарант : [сайт]. — URL: https://base.garant.ru/2160711/ (дата обращения: 17.08.2021).

2. Об утверждении Концепции федеральной целевой программы «Развитие мелиорации земель сельскохозяйственного назначения России на 2014-2020 годы» : распоряжение Правительства РФ от 22 января 2013 года, № 37-P / КонсультантПлюс : [сайт]. — URL: http://government.ru/docs/134/ (дата обращения: 17.08.2021).

Поступила в редакцию 25.06.2021

Запланирована в номер 20.07.2021 


\section{Об авторах:}

Тарасов А. С., главный специалист ФГБУ ГЦАС «Ростовский» (346735, РФ, Аксайский район, пос. Рассвет, ул. Институтская, 2), доктор экономических наук, доцент, al.tar@mail.ru

Тарасов С. А., преподаватель Новочеркасского колледжа промышленных технологий и управления (346400, РФ, г. Новочеркасск, ул. Александровская, 109 б), s23t@mail.ru

\section{References}

1. Ob utverzhdenii Koncepcii federal'noj celevoj programmy «Sohranenie i vosstanovlenie plodorodiya pochv zemel' sel'skohozyajstvennogo naznacheniya i agrolandshaftov kak nacional'nogo dostoyaniya Rossii na 2006-2010 gody» : rasporyazhenie Pravitel'stva RF ot1 oktyabrya 2005 goda № 1564-r [On approval of the Concept of the Federal target program "Preservation and restoration of soil fertility of agricultural lands and agricultural landscapes as the national heritage of Russia for 2006-2010": Decree of the Government of the Russian Federation No. 1564-r of October 1, 2005.] Garant. (In Russ.)

2. Ob utverzhdenii Koncepcii federal'noj celevoj programmy «Razvitie melioracii zemel' sel'skohozyajstvennogo naznacheniya Rossii na 2014-2020 gody»: rasporyazhenie Pravitel'stva RF ot 22 yanvarya 2013 goda, № 37-R [On approval of the Concept of the Federal target program "Development of agricultural land reclamation in Russia for 2014-2020": Decree of the Government of the Russian Federation, January 22, 2013, No. 37-R.] KonsultantPlus. (In Russ.)

Received 25.06.2021

Scheduled in the issue 20.07.2021

\section{Authors:}

Tarasov A. S. Chief Specialist of FSBU SCAS "Rostovskiy" (2, str. Institutskaya, Rassvet, Aksaiskiy region, 346735, RF), Doctor of Economics, associate professor, al.tar@mail.ru

Tarasov S. A. Lecturer, Novocherkassk College of Industrial Technologies and Management (109 b, Aleksandrovskaya str., Novocherkassk, 346400, RF), s23t@mail.ru 